\title{
Anemia and thrombocytopenia after delivery: a case study of thrombotic thrombocytopenic purpura
}

\author{
Gatske M. Nieuwenhuyzen-de Boer ${ }^{1}$, Metteke A. Kamping ${ }^{1}$, Sabina Kersting ${ }^{2}$ and Anneke Dijkman $^{3}$ \\ ${ }^{1}$ Department of Obstetrics and Gynecology, Erasmus MC Rotterdam, the Netherlands \\ ${ }^{2}$ Department of Hematology, HagaZiekenhuis Den Haag, the Netherlands \\ ${ }^{3}$ Department of Obstetrics and Gynecology, Reinier de Graaf Gasthuis Delft, the Netherlands
}

\begin{abstract} presentation without purpura and the similarity to hypertensive disorders. for TTP was started by prednisone, plasmapheresis and red cell and platelet transfusions.

\section{Introduction}

Thrombotic thrombocytopenic purpura (TTP) in pregnancy is rare, and can be a diagnostic challenge because of its clinical similarity to pre-eclamptic disorders. Without treatment, mortality rate of TTP is more than $90 \%$, therefore early recognition of TTP is important. Treatment with plasma transfusions and plasmapheresis decreases the mortality rate to $20 \%$ [1]. We report a case of TTP discovered postpartum. Written consent of the patient was obtained.
\end{abstract}

A case with the rare, life threatening thrombotic thrombocytopenic purpura (TTP) was discovered after delivery. Diagnosis was delayed because of the unusual

We describe a patient just after delivery with proteinuria and severe thrombocytopenia, platelets declined to 18x109/L. Thrombotic thrombocytopenic purpura (TTP) was suspected. TTP was confirmed by determining the activity of the ADAMTS-13 enzyme, which was $0 \%$. Our patient was referred to a tertiary unit, where therapy

In this case study, the diagnosis of TTP was delayed due to the similarity to pre-eclamptic disorders and the absence of clinical features of TTP. In this case a baby was born after intrapartum fetal distress. Further research is required to determine whether TTP may contribute to this.

\section{Case presentation}

A 25-year-old healthy primigravida of Polish nationality was admitted to our hospital at 40 weeks of gestation for obstetric pain control at $5-\mathrm{cm}$ dilation. Antenatal checkups had taken place in a community-based primary care facility for midwifery. Due to rapid progression in dilation, no pain relief could be started. During the second stage of labour, intermittent auscultation demonstrated fetal heart rate decelerations persisting after the contractions. Continuous electronic fetal monitoring confirmed fetal distress, therefore a vacuumassisted delivery was performed. After three tractions a boy was born of 3470 grams, on the $20-50^{\text {th }}$ percentile for gestational age. Apgar scores after 1, 5 and 10 minutes were respectively 6,8 and 9 . Arterial umbilical cord $\mathrm{pH}$ was 6.98 with a Base Excess of $-16.7 \mathrm{mmol} / \mathrm{L}$. Placenta delivery was spontaneous and complete, with good contraction of the uterus and total blood loss was 500 millilitres.

After the afterbirth, the patient became pale and temporarily less responsive. Vital signs demonstrated a heart rate of $126 \mathrm{bpm}$, blood pressure $74 / 36 \mathrm{mmHg}$, oxygen saturation $98 \%$ and temperature $37.2^{\circ} \mathrm{C}$. Intravenous fluid replacement corrected the hypotension. Inversion of the uterus was ruled out by physical examination and trans-abdominal ultrasound.
Laboratory findings revealed a severe anemia with hemoglobin of $6.3 \mathrm{~g} / \mathrm{dL}$ and thrombocytopenia with bloodplatelets of $26 \times 10^{9} / \mathrm{L}$. The patient was diagnosed with HELLP (hemolysis, elevated liver enzymes, low platelets) syndrome. Expanded laboratory analysis demonstrated: uric acid $0.50 \mathrm{mmol} / \mathrm{L}$; creatinine $104 \mathrm{umol} / \mathrm{L}$; aspartate transaminase (AST) $52 \mathrm{IU} / \mathrm{L}$; alanine transaminase (ALT) 18IU/L, lactate dehydrogenase (LD) $861 \mathrm{IU} / \mathrm{L}$ ). We started preventive anticonvulsant treatment by intravenous magnesium sulphate, and the patient was given a blood transfusion of packed red blood cells.

The neonate was examined by the pediatrician and admitted to the neonatology department. Blood platelets of the neonate were normal $\left(170 \times 10^{9} / \mathrm{L}\right)$. Because of rapid clinical recovery, no blood test was performed to determine $\mathrm{pH}$ again until the neonate was 4 hours old. At that time $\mathrm{pH}$ was normalized at 7.35 and base excess was -5 .

On the sixth day postpartum our patient was still anemic despite six packed red blood cells transfusions. Hemoglobin level was $6.9 \mathrm{mg} /$ $\mathrm{dL}$ and platelets declined to $18 \times 10^{9} / \mathrm{L}$. The diagnosis was revised, thrombotic thrombocytopenic purpura (TTP) was suspected. TTP was confirmed by determining the activity of the ADAMTS-13 enzyme, which was $0 \%$. Our patient was referred to a tertiary unit, where therapy for TTP was started by prednisone, plasmapheresis and red cell and platelet transfusions. The activity of ADAMTS-13 rose to $56 \%$ after

Correspondence to: Gatske M. Nieuwenhuyzen-de Boer, Department of Obstetrics and Gynecology, Erasmus MC, University Medical Center Rotterdam, P.O.2040, 3000 CA Rotterdam, The Netherlands, Tel: +31 10 7040704, E-mail: g.nieuwenhuyzen-deboer@erasmusmc.nl

Key words: pregnancy, thrombotic thrombocytopenic purpura (TTP), anemia, thrombocytopenia

Received: March 28, 2016; Accepted: APril 18, 2016; Published: April 22, 2016 
the first plasmapheresis, to $65 \%$ after the second and blood platelets increased to $143 \times 10^{9} / \mathrm{L}$. After six plasmapheresis treatments the patient was discharged from the hospital to the outpatient clinic, where she received two more plasmaphereses at 8 and 12 days postpartum. At the $12^{\text {th }}$ day hemoglobin was $11.8 \mathrm{~g} / \mathrm{dL}$, thrombocytes $485 \times 10^{9} / \mathrm{L}$ and LD 240IU/L.

In retrospect, in this case signs of pre-eclampsia, HELLP syndrome or TTP appeared to have been present before labor. At the last antenatal checkup, at 39 weeks and five days of gestation, the patient had complained of peripheral edema and had been tested positive for albumin by an automated reagent-strip reading device, with a normal blood pressure of $118 / 72 \mathrm{mmHg}$. Two days later she was examined again and still had isolated proteinuria. Because of the absence of hypertension and other signs of pre-eclampsia, the patient was not referred to an obstetric unit. After the afterbirth, the patient collapsed and showed signs of severe anemia and thrombocytopenia, which were primarily diagnosed as HELLP syndrome and six days later revised to thrombotic thrombocytopenic purpura.

\section{Background}

Thrombocytopenia affects up to ten percent of all pregnancies, ranging from mild $\left(100-150 \times 10^{9} / \mathrm{l}\right)$ to moderate $\left(50-10 \times 10^{9} / \mathrm{l}\right)$ and severe $\left(<50 \times 10^{9} / 1\right)$ [2,3]. Thrombocytopenia has two major causes: impaired platelet production by the bone marrow as a result of many different non-pregnancy specific causes, or increased platelets destruction.

During pregnancy thrombocytopenia can be a symptom of preeclampsia or HELLP syndrome, but it can also be the result of idiopathic (autoimmune) thrombocytopenia (ITP), a bleeding disorder in which certain immune system cells produce antibodies that destroy platelets. The platelet count can be extremely low in ITP. However, our case also demonstrated severe anemia. The combination of thrombocytopenia and microangiopatic hemolytic anemia, leading to hemolysis, and specific multi-organ damage, can, amongst others, be typically found in Hemolitic Uremic Syndrome (HUS) and TTP, both headed under the category of thrombotic microangiopathies (TMA's). However, it can also be found in pre-eclampsia or HELLP syndrome. Therefore this combination can be a diagnostic challenge during pregnancy.

In HUS manifestation of acute renal failure and hypertension is typical, as well as microangiopathic anemia and thrombocytopenia. Renal dysfunction in HUS is often more severe than in TTP, whereas neurologic abnormalities are more prevalent in TTP. HUS is mostly observed in children with a preceding gastrointestinal infection; but has been reported in adults and pregnant patients [4]. In HUS without diarrhea, plasmapheresis or plasma infusion is indicated $[5,6]$.

For TTP diagnosis is made by clinical presentation of the combination of neurologic abnormalities, thrombocytopenia, microangiopathic hemolytic anemia, fever, and renal dysfunction ${ }^{4}$. Pregnancy is thought to precipitate the disorder's first occurrence, or can exacerbate its recurrence in patients with known prior TTP [4,7]. In a review of published cases from 1964 to 2002, the frequency of pregnancy among patients diagnosed with TTP-HUS was $13 \%$ [8]. TTP is strongly associated with severe deficiency of the activity of ADAMTS-13, a metalloprotease that cleaves vonWillebrand factor multimers. ADAMTS-13 deficiency causes extensive platelet adhesion and clumping, leading to severe thrombocytopenia and microangiopathic hemolytic anemia.
The lack of ADAMTS-13 can be acquired or can be the result of auto-antibodies. On rare occasions, TTP is a result of an inherited deficiency of ADAMTS-13, called congenital TTP or UpshawSchulman syndrome. Recurrence of TTP is found in $20-50 \%$ of patients [9]. Because of the high risk of complications in future pregnancies, patients with prior TTP require close monitoring during pregnancy and after delivery, including ADAMTS-13 assessments. Growth restriction is frequently seen in pregnancies complicated by TTP $[10,11]$ and stillbirth rate has been $17 \%$ since 1996 [7].

Distinction between TTP and HUS is usually based on clinical presentation. TTP and HUS are rare in the general population, and in pregnancy TTP and HUS together occur in one out of 25.000 cases [10]. Recognition of TTP and HUS is vital, since the condition will not be relieved spontaneously or by delivery.

Pre-eclampsia and HELLP syndrome affect up to six percent of all first pregnancies [12]. The definition of pre-eclampsia is a combination of pregnancy induced hypertension and proteinuria of $300 \mathrm{mg} / 24$ hours. Thrombocytopenia occurs in $50 \%$ of the cases. Because this case lacked hypertension, HELLP syndrome was suspected. HELLP syndrome affects $0.5 \%$ to $0.9 \%$ of all pregnancies, and develops in ten percent of patients with pre-eclampsia [13]. Criteria involve microangiopathic, hemolytic anemia, high LD, increased AST and thrombocytopenia. Approximately $75 \%$ of HELLP-patients have proteinuria, and only 50 to $60 \%$ have hypertension.

Severe pre-eclampsia or HELLP syndrome and TTP can be hard to distinguish, because both demonstrate microangiopathic hemolytic anemia combined with thrombocytopenia and can have proteinuria. In 2008, Martin et al. reviewed 166 pregnancies complicated by TTP and found that pregnancy-associated TTP was complicated by concurrent pre-eclampsia/ HELLP syndrome in $17.5 \%$ of the patients. This combination of TTP and pre-eclampsia or HELLP syndrome increased maternal mortality to $44.4 \%$, versus $21.8 \%$ in a group of TTP without pre-eclampsia/ HELLP [7].

Because of this case of TTP we wondered if severe perinatal asphyxia could be related to the severe thrombocytopenia or the severe maternal anemia of $6.3 \mathrm{~g} / \mathrm{dL}$. Literature was searched for the effects of anemia and thrombocytopenia on neonatal outcome.

In 2006, Parnas described a study of 199 pregnant patients with thrombocytopenia, platelets cut-off below $100 \times 109 / 1$, of different etiologies, including one case of TTP. Thrombocytopenia was significantly associated with more preterm delivery (OR 3.14, 95\% CI1.7-6.0, $\mathrm{p}<0.001$ ), higher rates of placental abruption (OR 6.2, 95\% CI 1.7-33.2, $\mathrm{p}=0.001)$, higher rates of Apgar scores $<7$ at $5 \mathrm{~min}(\mathrm{OR}=6.3$, 95\% $\mathrm{CI}=1.8-33.8, \mathrm{p}=0.001$ ), intrauterine growth restriction (IUGR; $\mathrm{OR}=4.6,95 \% \mathrm{CI}=1.5-19.1, \mathrm{p}=0.003)$ and stillbirth $(65 / 1000$ versus 0 $\mathrm{p}<0.001)$. Patients with gestational thrombocytopenia and immune thrombocytopenic purpura had favorable maternal and perinatal outcomes, but on the other hand the rarer and more severe group of causes of thrombocytopenia, including disseminated intravascular coagulation, TTP, anti-phospholipid antibodies syndrome, and myeloproliferative disease were associated with placental abruption, Apgar scores below 7 at 1 and 5 minutes, and stillbirths [14]. The perinatal asphyxia in this case might be related to the thrombocytopenia.

Maternal anemia, defined by the World Health Organization in pregnancy as 'haemoglobin levels of $11 \mathrm{~g} / \mathrm{dL}$ or less', signifies preplacental hypoxia. In case of anemia, maternal blood entering the intervillous space is hypoxemic, with potential consequences of hypoxia 
for the mother, placenta and fetus. Therefore fetal distress during delivery is conceivable, although the extent to which maternal anemia affects neonatal outcome is still uncertain. Some studies, performed in developing as well as in developed countries, documented a strong association between low hemoglobin before delivery and sub-optimal fetal outcome. This included low birth weight $[15,16]$, preterm delivery [15], perinatal mortality [16] and more cesarean sections due to fetal distress ${ }^{15}$. However, other investigators did not find any significant associations [15,17] and no significant differences were noted in Apgar scores after 5 minutes below 7 [16,17]. In 2000, a meta-analysis of Xiong noted that few studies had examined the relationship between maternal anemia and perinatal mortality, and he concluded that the relationship between anemia and perinatal mortality was still inconclusive [18]. No distinction was made with respect to the severity of anemia.

\section{Conclusions}

In this case study, the diagnosis of TTP was delayed due to the similarity to pre-eclamptic disorders and the absence of clinical features of TTP. Since early initiation of appropriate treatment is essential for maternal and neonatal outcome, several important lessons are inherent to this case. Firstly, unexplained proteinuria always requires further medical analysis. A blood count most likely would have revealed anemia and thrombocytopenia ante partum. Secondly, if anemia and thrombocytopenia do not improve postpartum despite several blood transfusions, the diagnosis HELLP-syndrome needs to be revised, even if no clinical features of TTP are present. Thirdly, further research is required to determine whether severe anemia and thrombocytopenia may contribute to acute intrapartum fetal distress.

\section{Disclosure of interests}

The authors report no conflict of interest.

\section{Authors' contributions}

GMN and MAK were responsible for the data collection and literature review. SK was responsible for the supervision of the hematologic aspects; $\mathrm{AD}$ was responsible for supervising the obstetric aspects. All authors were responsible for manuscript editing.

\section{Details of ethics approval}

Written consent was obtained from de discussed patient.

\section{References}

1. Michael M, Elliott EJ, Ridley GF, Hodson EM, Craig JC (2009) Interventions for haemolyticuraemic syndrome and thrombotic thrombocytopenic purpura.Cochrane Database Syst Rev: CD003595. [Crossref]

2. Onisai M, Vladareanu AM, Delcea C, Ciorascu M, Bumbea H, et al. (2012) Perinatal outcome for pregnancies complicated with thrombocytopenia. J Matern Fetal Neonatal Med 25: 1622-1626. [Crossref]

3. McCrae KR (2010) Thrombocytopenia in pregnancy. Hematology Am SocHematolEduc Program 2010: 397-402. [Crossref]

4. Pels SG, Paidas MJ (2011) Microangiopathic disorders in pregnancy. HematolOncolClin North Am 25: 311-322, viii. [Crossref]

5. Caprioli J, Noris M, Brioschi S, Pianetti G, Castelletti F, et al. (2006) Genetics of HUS: the impact of MCP, $\mathrm{CFH}$, and IF mutations on clinical presentation, response to treatment, and outcome. Blood 108: 1267-1279. [Crossref]

6. Fang CJ, Richards A, Liszewski MK, Kavanagh D, Atkinson JP (2008) Advances in understanding of pathogenesis of aHUS and HELLP. Br J Haematol 143: 336-348. [Crossref]

7. Martin JN Jr, Bailey AP, Rehberg JF, Owens MT, Keiser SD, et al. (2008) Thrombotic thrombocytopenic purpura in 166 pregnancies: 1955-2006. Am J ObstetGynecol 199: 98-104. [Crossref]

8. George JN (2003) The association of pregnancy with thrombotic thrombocytopenic purpura-hemolytic uremic syndrome. CurrOpinHematol 10: 339-344. [Crossref]

9. Peyvandi F, Lavoretano S, Palla R, Feys HB, Vanhoorelbeke K, et al. (2008) ADAMTS13 and anti-ADAMTS13 antibodies as markers for recurrence of acquired thrombotic thrombocytopenic purpura during remission. Haematologica 93:232-239. [Crossref]

10. Dashe JS, Ramin SM, Cunningham FG (1998)The long-term consequences of thrombotic microangiopathy (thrombotic thrombocytopenic purpura and hemolytic uremic syndrome) in pregnancy. Obstet Gynecol91:662-668.[Crossref]

11. Ducloy-Bouthors AS, Caron C, Subtil D, Provot F, Tournoys A, et al. (2003) Thrombotic thrombocytopenic purpura: medical and biological monitoring of six pregnancies. Eur J ObstetGynecolReprodBiol111:146-152. [Crossref]

12. ACOG Committee on Practice Bulletins--Obstetrics (2002) ACOG practice bulletin Diagnosis and management of preeclampsia and eclampsia. Number 33, January 2002. ObstetGynecol99: 159-167. [Crossref]

13. Kirkpatrick CA (2010) The HELLP syndrome. ActaClinBelg65: 91-97. [Crossref]

14. Parnas M, Sheiner E, Shoham-Vardi I, Burstein E, Yermiahu T, et al. (2006) Moderate to severe thrombocytopenia during pregnancy. Eur J ObstetGynecolReprodBiol128: 163-168. [Crossref]

15. Hwang HS, Kim YH, Kwon JY, Park YW (2010) Uterine and umbilical artery Doppler velocimetry as a predictor for adverse pregnancy outcomes in pregnant women with anemia. J Perinat Med 38: 467-471. [Crossref]

16. Lone FW, Qureshi RN, Emanuel F (2004) Maternalanaemia and its impact on perinatal outcome. Trop Med Int Health 9: 486-490. [Crossref]

17. Lao TT, Pun TC (1996) Anaemia in pregnancy--is the current definition meaningful? Eur J ObstetGynecolReprodBiol 68: 53-58. [Crossref]

18. Xiong X, Buekens P, Alexander S, Demianczuk N, Wollast E (2000) Anemia during pregnancy and birth outcome: a meta-analysis. Am J Perinatol17: 137-146. [Crossref]

Copyright: (C2016 Nieuwenhuyzen-de Boer GM. This is an open-access article distributed under the terms of the Creative Commons Attribution License, which permits unrestricted use, distribution, and reproduction in any medium, provided the original author and source are credited. 